\title{
Distinct expression patterns of $\beta-1,3$-glucanases and chitinases during the germination of Solanaceous seeds
}

\author{
Luciana Petruzzelli', Kerstin Müller², Katrin Hermann² and Gerhard Leubner-Metzger ${ }^{2 *}$ \\ ${ }^{1}$ Istituto Biosintesi Vegetali, C.N.R., via Bassini 15, I-20133 Milano, Italy; ${ }^{2}$ Institut für Biologie II, Albert-Ludwigs- \\ Universität, Schänzlestr. 1, D-79104 Freiburg i. Br., Germany
}

\begin{abstract}
The expression patterns of $\beta-1,3-$ glucanases ( $\beta$ Glu) and chitinases (Chn) were investigated during the seed germination of members of the Cestroideae (three Nicotiana species, Petunia hybrida) and the Solanoideae (Capsicum annuum, Physalis peruviana) subgroups of Solanaceous species. Rupture of the micropylar testa (seed coat) and rupture of the micropylar endosperm, i.e. radicle emergence, were distinct and temporally separate events during the germination of Cestroideaetype seeds. $\beta$ Glu accumulation in imbibed Cestroideaetype seeds, occurring after testa rupture but prior to endosperm rupture, was inhibited by abscisic acid (ABA) and promoted by gibberellins (GA) and light, in strict association with germination, and appeared to be caused by transcriptional regulation of the class I $\beta$ Glu genes. The micropylar cap of Solanoideae-type seeds does not allow a distinction between testa and endosperm rupture, but $\beta$ Glu accumulation occurred prior to radicle emergence of pepper and $P$. peruviana seeds. ABA inhibited endosperm rupture and $\beta$ Glu accumulation in the micropylar cap of pepper seeds. In contrast to tomato, $\beta$ Glu accumulation in pepper seeds was not only confined to the micropylar cap, was due to distinct, tissue-specific $\beta$ Glu isoforms, and was not accompanied by Chn accumulation. In conclusion, ABA inhibition of germination and $\beta$ Glu accumulation in the micropylar endosperm appears to be a widespread event during the seed germination of Solanaceous species. In contrast, accumulation of $\mathrm{Chn}$ and distinct $\beta \mathrm{Glu}$ isoforms in the embryo, prior to germination, appears to be a speciesspecific phenomenon within the Solanaceae. In addition, a post-germination co-induction of $\beta$ Glu and $\mathrm{Chn}$ in the root of the emerged seedling was found in endospermic
\end{abstract}

\footnotetext{
${ }^{*}$ Correspondence

Fax: + 497612032612

Email: leubner@uni-freiburg.de

Web site: 'The Seed Biology Place' http: / / www.leubner.ch Abbreviations: $\mathrm{ABA}=$ abscisic acid; $\mathrm{Chn}=$ chitinase; $\mathrm{Chn} \mathrm{I}=$ class I chitinase; $\mathrm{GA}=$ gibberellin; $\beta \mathrm{Glu}=\beta$-1,3-glucanase; $\beta$ Glu I = class I $\beta$-1,3-glucanase.
}

and non-endospermic species and could represent an evolutionarily conserved event during dicot seedling development.

Keywords: abscisic acid, Capsicum, chitinase,
gibberellin, $\beta-1,3$-glucanase, Nicotiana, seed
germination, Solanaceae family

\section{Introduction}

The intrafamilial relationships of Solanaceous species have been investigated using morphological and molecular criteria. On the morphological level, the Solanaceae family can be divided into two large subgroups (Judd et al., 1999): (1) The Cestroideae subgroup, e.g. Nicotiana and Petunia, is characterized by straight to slightly bent embryos and prismatic to subglobose seeds, and typically by capsules; and (2) the Solanoideae subgroup, e.g. Capsicum, Lycopersicon and Physalis, is characterized by curved embryos and flattened, discoid seeds and often by berries. Seed germination of tobacco (Nicotiana tabacum) and tomato (Lycopersicon esculentum), type members for each of the two subgroups, is regulated by the balance of forces between the growth potential of the embryo and the micropylar layers that cover the radicle tip and function as a constraint to radicle protrusion (reviewed by Hilhorst, 1995; Bewley, 1997b; Koornneef et al., 2002; Leubner-Metzger, 2003). These covering layers are the testa (seed coat), an entirely maternal tissue, and the triploid endosperm, a predominantly maternal tissue. Both micropylar layers are involved in controlling tobacco and tomato coat-imposed dormancy (e.g. Hilhorst and Downie, 1996; Nonogaki et al., 2000; Wu et al., 2000; Leubner-Metzger, 2002).

Surgical removal of the micropylar testa and the endosperm tissues permits radicle growth under conditions that inhibit germination of intact seeds of tobacco (Bihlmeier, 1927; Kincaid, 1935) and tomato (Liptay and Schopfer, 1983; Hilhorst, 1995). Microscopic studies in tobacco showed that storage 
reserves are degraded in the micropylar endosperm cells prior to protrusion by the radicle and that the endospermic hole, which has a smooth outline and is always formed at the micropylar end of germinating tobacco seeds, results from tissue dissolution rather than from the pushing action of the protruding radicle (Arcila and Mohapatra, 1983; LeubnerMetzger, 2002). Similar observations are obvious for other Solanaceous species and are correlated with weakening of the micropylar endosperm, e.g. in tomato (Hilhorst, 1995; Bewley, 1997a; Toorop et al., 2000) and in pepper (Watkins and Cantliffe, 1983; Watkins et al., 1985).

Rupture of the micropylar testa and the micropylar endosperm, resulting in radicle emergence, are distinct and temporally separate events during the germination of tobacco seeds (Arcila and Mohapatra, 1983; Leubner-Metzger et al., 1995; Web site: http:/ / www.leubner.ch/). Treatment of imbibed tobacco seeds with abscisic acid (ABA) specifically delays endosperm rupture, but not testa rupture, and results in the formation of a novel structure, consisting of the enlarging radicle covered by a sheath of greatly elongated micropylar endosperm.

As in Cestroideae-type seeds, $\beta$ Glu also accumulates prior to endosperm rupture in Solanoideae-type tomato seeds (Wu et al., 2000). The micropylar-covering layers of these types of seeds are organized in cap-like structures, but a distinction between testa and endosperm rupture is not possible (Watkins and Cantliffe, 1983; Watkins et al., 1985; Hilhorst, 1995; Judd et al., 1999; Nonogaki et al., 2000). ABA also inhibits tomato endosperm rupture, i.e. radicle emergence of tomato seeds (Hilhorst, 1995; Toorop et al., 2000; Wu et al., 2000). Gibberellin (GA)induced weakening of the micropylar endosperm cap is required for tomato and pepper seed germination, and the GA-deficient gib1 mutant of tomato does not germinate without GA treatment (e.g. Watkins and Cantliffe, 1983; Watkins et al., 1985; Hilhorst, 1995; Bewley, 1997a; Nonogaki et al., 2000; Wu et al., 2000). Weakening of the micropylar endosperm is likely to be achieved by cell-wall hydrolysis by the action of GA-induced cell-wall hydrolases.

Prior to radicle protrusion, two phases can be distinguished in tomato: (1) the early phase is not inhibited by $\mathrm{ABA}$ and includes $\mathrm{ABA}$-insensitive endosperm weakening associated with micropylarendosperm-specific, ABA-independent expression of endo- $\beta$-mannanase and other proteins; $A B A$ inhibits BGlu I expression (e.g. Bewley, 1997a; Toorop et al., 1998, 2000; Nonogaki et al., 2000; Wu et al., 2000). Endo- $\beta$-mannanase, which can hydrolyse isolated micropylar endosperm cell walls in vitro, appears to be necessary for endosperm weakening, but is not sufficient for the completion of tomato germination, and its accumulation is not inhibited by ABA. (2) The late phase is critical, since it includes the final ABAcontrolled step of radicle emergence. It is associated with ABA-sensitive $\beta$ Glu I expression in the micropylar endosperm, and $\beta$ Glu I, therefore, could contribute to radicle emergence of tomato ( $\mathrm{Wu}$ et al., 2000; Leubner-Metzger, 2003). It has been proposed that the late phase includes a second, ABA-controlled step of endosperm weakening, which thereby is a biphasic process in tomato (Toorop et al., 2000).

On the molecular level, phylogenetic analyses of the multigene families of $\beta$-1,3-glucanases ( $\beta$ Glu) and chitinases (Chn) showed that their organization is highly conserved within the Solanaceae (e.g. Sperisen et al., 1991; Meins et al., 1992; Van Buuren et al., 1992; Simmons, 1994). Based on the amino acid sequences of the mature proteins, the various $\beta \mathrm{Glu}$ and $\mathrm{Chn}$ have been grouped into structural classes that differ in sequence identity by at least $40-50 \%$. At least three structural classes are identified for the highly homologous $\beta$ Glu isoforms of tobacco, tomato, potato and pepper. These conserved evolutionary relationships are also manifested on the level of the hormonal regulation of the orthologous genes. For example, ethylene treatment results in the transcriptional co-induction of the class I isoforms of $\beta$ Glu ( $\beta$ Glu I) and Chn (Chn I) in the leaves of tobacco and tomato. ABA transcriptionally down-regulates BGlu I, but not Chn I, of tobacco and tomato (Rezzonico et al., 1998; Leubner-Metzger and Meins, 1999; Wu et al., 2000).

Seed germination of tobacco and tomato is associated with the transcriptional induction of the $\beta$ Glu I genes just prior to radicle emergence (LeubnerMetzger et al., 1995; Wu et al., 2000; Leubner-Metzger, 2001). This induction is highly confined to the micropylar endosperm, and $\beta$ Glu I accumulation and endosperm rupture of both species are promoted by GA and inhibited by ABA. Sense transformation of tobacco with a chimeric ABA-inducible $\beta$ Glu I transgene provided direct evidence that $\beta$ Glu I contributes to endosperm rupture (Leubner-Metzger and Meins, 2000). In tomato, but not in tobacco, Chn I also accumulates in the micropylar endosperm prior to radicle emergence. In contrast to $\beta$ Glu I, and in agreement with the situation in vegetative tissues, Chn I accumulation in imbibed tomato seeds is not inhibited by ABA. Thus, the hormonal regulation of BGlu I induction and endosperm rupture of Cestroideae-type (tobacco) and Solanoideae-type (tomato) seeds is similar, but the two seed types differ with respect to Chn expression. However, since only one type-member of each subgroup has been investigated so far, no general conclusions with respect to similarities and differences in the tissuespecific and hormonal regulation of $\beta$ Glu and $\mathrm{Chn}$ among Solanaceous seeds can be drawn. 


\section{Materials and methods}

\section{Plant materials and germination conditions}

Mature seeds of Capsicum annuum L. cv. Toro (ESASEM, Milano, Italy), Physalis peruviana L. (Wyss Samen und Pflanzen AG, Zuchwil-Solothurn, Switzerland), Petunia hybrida Hort. (Vilm.) (Plantania seeds, OBI and Royal Lemkes, Bleiswijk, The Netherlands), Nicotiana sylvestris Speg \& Comes, Nicotiana plumbaginifolia Viv., and Nicotiana tabacum L. cv. Havana 425 (Agricultural Experimental Station, University of Wisconsin, Madison, Wisconsin, USA) were used for germination analyses, performed as described earlier (Leubner-Metzger et al., 1998). In brief, 100-150 seeds (c. 20 seeds for $C$. annuum and $P$. peruviana) were sown in 9-cm-diameter plastic Petri dishes containing filter paper wetted with a nutrient solution (control medium) supplemented as indicated with $10 \mu \mathrm{M}$ cis-( \pm )-abscisic acid (ABA, Sigma, St. Louis, Missouri, USA) and $10 \mu \mathrm{M}$ gibberellin $\mathrm{A}_{4}\left(\mathrm{GA}_{4}\right.$ Sigma). Petri dishes were incubated at $24^{\circ} \mathrm{C}$ in continuous white light (3000 lux, Philips 'TL'D $35 \mathrm{~W} / 33$ lamps) or in darkness. After scoring for germination, seeds were stored at $-70^{\circ} \mathrm{C}$ for subsequent analyses.

\section{Analysis of proteins and RNA}

Procedures for extracting proteins, assays for enzyme activity, immunoblot analysis, and protein determination have been described previously (Leubner-Metzger et al., 1995). In brief, $\beta$ Glu and Chn activities were assayed radiometrically using reduced $\left[{ }^{3} \mathrm{H}\right]$ laminarin and $\left[{ }^{3} \mathrm{H}\right]$ chitin as the substrates, which are specifically digested by endo-type $\beta \mathrm{Glu}$ and $\mathrm{Chn}$, respectively. The polyclonal rabbit anti-tobacco $\beta$ Glu I antibody used for immunoblot analysis is known to detect the class I, class II and class III isoforms of $N$. tabacum and N. sylvestris (Neuhaus et al., 1992; Beffa et al., 1993; Kunz et al., 2001) and is known to cross-react with the BGlu I of tomato (Wu et al., 2000) and pea (Petruzzelli et al., 1999). The polyclonal rabbit antitobacco Chn I antibody used for immunoblot analysis is known to detect the Chn I isoforms of N. tabacum, N. sylvestris (Kunz et al., 2001) and tomato (Wu et al., 2000). Preparation of total RNA and RNA-blot hybridization were as described by Leubner-Metzger et al. (1995). The probes were radiolabelled with $\left[\alpha^{-32} \mathrm{P}\right] \mathrm{dCTP}$ by random priming (rediprime kit; Amersham, Buckinghamshire, UK), using as templates the $c .1 \mathrm{~kb}$ PstI fragments of the tobacco cDNAs for $\beta$ Glu I (Shinshi et al., 1988) and Chn I (Shinshi et al., 1987), and the $1.8 \mathrm{~kb}$ EcoRI fragment of genomic DNA encoding tomato $18 \mathrm{~S}$ ribosomal RNA (Schmidt-Puchta et al., 1989). Hybridized membranes were washed at high stringency [20 min at $62^{\circ} \mathrm{C}$ in $0.1 \%(\mathrm{w} / \mathrm{v}) \mathrm{SDS}, 30 \mathrm{mM}$ $\mathrm{NaCl}, 3 \mathrm{mM}$ sodium citrate, $\mathrm{pH}$ 7.0].

\section{Results}

\section{ABA-sensitive $\beta$ Glu is induced after testa rupture, but prior to endosperm rupture in Cestroideae-type seeds}

Testa rupture and endosperm rupture are distinct and temporally separate events during the germination of tobacco seeds (Arcila and Mohapatra, 1983; LeubnerMetzger et al., 1995). In initial experiments we investigated whether this is also the case for other Nicotiana species and for Petunia hybrida, which all belong to the Cestroideae subgroup of Solanaceae (Judd et al., 1999). Testa rupture also precedes endosperm rupture of $N$. plumbaginifolia, $N$. sylvestris and $P$. hybrida (Table 1). Seed germination of many Nicotiana species requires light, and, in agreement with this, neither testa rupture nor endosperm rupture was observed in N. tabacum, N. plumbaginifolia and $N$. sylvestris seeds imbibed in darkness (Table 1; LeubnerMetzger, 2003). In contrast to N. tabacum, N. sylvestris, and $P$. hybrida, light alone was not sufficient to induce testa rupture and germination of imbibed $N$. plumbaginifolia seeds, but treatment with $10 \mu \mathrm{M} \mathrm{GA}_{4}$ induced testa rupture and subsequent endosperm rupture (Table 1). Furthermore, as in tobacco, ABA treatment of seeds inhibited endosperm rupture, but did not affect testa rupture of the three Nicotiana species or of petunia.

Reduced [ $\left.{ }^{3} \mathrm{H}\right]$ laminarin, an algal $\beta-1,3$-glucan known to be specifically digested by all endo-type $\beta$ Glu isoforms (Leubner-Metzger et al., 1995), was utilized for the $\beta$ Glu assays. As in tobacco, $\beta$ Glu activity accumulated after testa rupture, but prior to endosperm rupture in germinating seeds of $N$. plumbaginifolia, N. sylvestris and P. hybrida (Table 1 ). No accumulation of $\beta$ Glu activity was found under the conditions where these species did not germinate, i.e. in dark-imbibed $N$. sylvestris seeds and in lightimbibed N. plumbaginifolia seeds without GA treatment. ABA treatment not only inhibited endosperm rupture, but also inhibited the accumulation of $\beta$ Glu activities in the different Nicotiana species and in petunia (Table 1; LeubnerMetzger et al., 1995). BGlu activity accumulation in the micropylar endosperm during tobacco seed germination appears to be due to the transcriptional induction of the $\beta$ Glu I genes. RNA-blot and immunoblot analyses presented in Fig. 1 support the view that this is also the case in the different Nicotiana species and in petunia. A tobacco $\beta$ Glu I cDNA probe detected a c. $1.6 \mathrm{~kb}$ transcript in germinating $N$. 


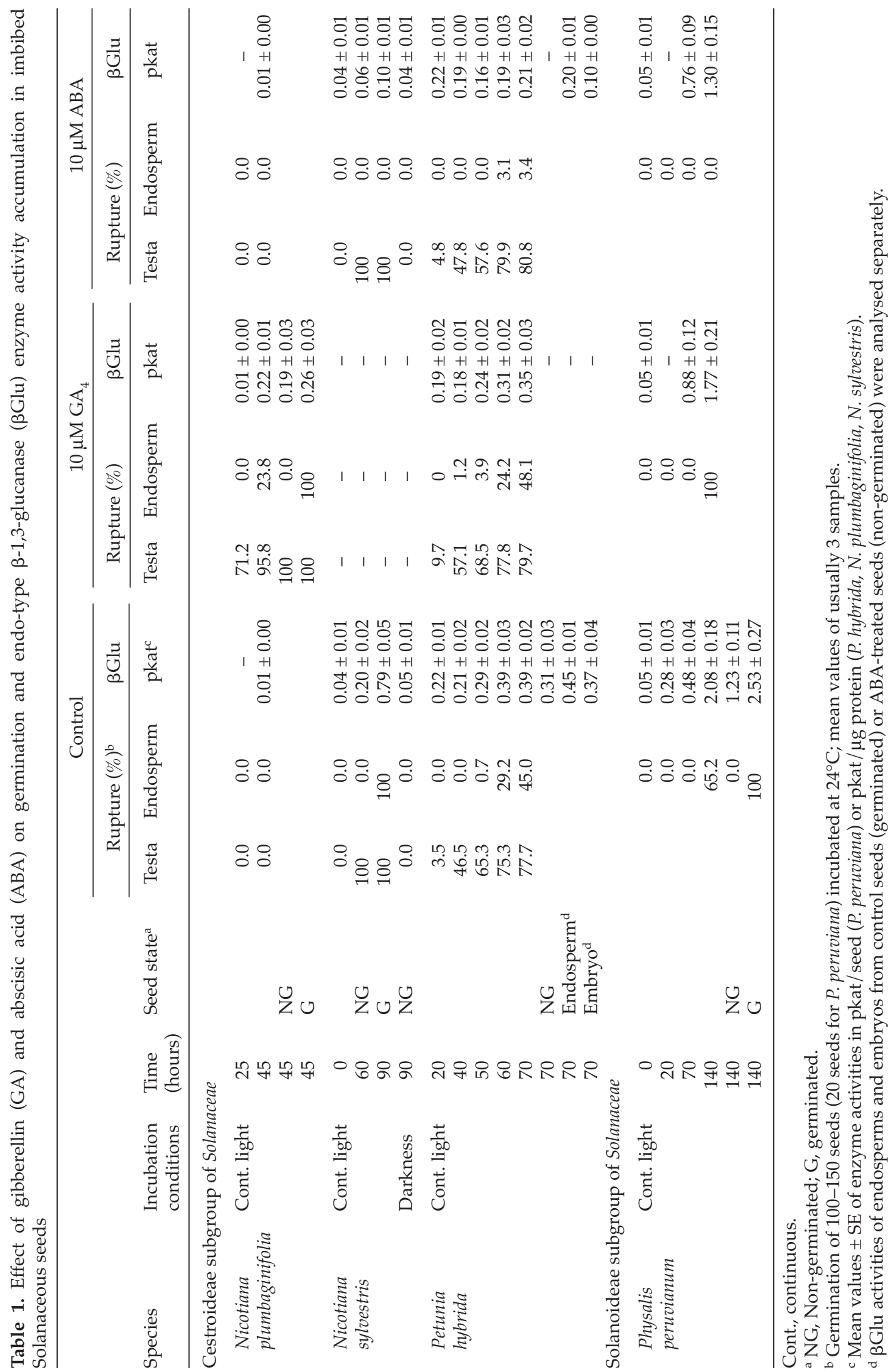


plumbaginifolia seeds, but only upon GA treatment and not in non-germinating seeds (Fig. 1A). The rabbit anti-tobacco $\beta$ Glu I antibody used for immunoblot analysis is known to detect the class I, class II and class III $\beta$ Glu isoforms of $N$. tabacum and N. sylvestris (Neuhaus et al., 1992; Beffa et al., 1993). This antibody detected the accumulation of immunoreactive bands in germinating seeds of $N$. sylvestris imbibed in the light (c. $33 \mathrm{kDa}$; data not shown) and of N. plumbaginifolia imbibed in the light and treated with GA (c. $34 \mathrm{kDa}$; Fig. 1B). The sizes of these bands are in agreement with the known sizes of the BGlu I of these species (Castresana et al., 1990; Gheysen et al., 1990; Neuhaus et al., 1992), and the bands were not detected in seeds imbibed under conditions that prevent or inhibit germination. The initial $\beta$ Glu activities in seeds of the three Nicotiana species are essentially background level (Table 1), and the $\beta$ Glu I accumulation during imbibition is localized exclusively in the endosperm (data not shown; Leubner-Metzger et al., 1995). In contrast to Nicotiana seeds, the initial $\beta$ Glu activities of petunia seeds were considerably higher, and $\beta$ Glu activity accumulation during imbibition was localized in the endosperm and in the embryo (Table 1). Figure 1C shows that the anti-tobacco $\beta$ Glu I antibody detects several immunoreactive bands $(27,30,35,43,47$ and $50 \mathrm{kDa}$ in size) in the protein extracts of germinating petunia seeds. The 27, 30, 47 and $50 \mathrm{kDa}$ bands did not show appreciable regulation with respect to the germination process and to the hormone treatments. In contrast, the $35 \mathrm{kDa}$ and the $43 \mathrm{Da}$ bands appeared to be down-regulated by $\mathrm{ABA}$ and up-regulated by imbibition and/or GA, in agreement with the $\beta$ Glu activities. These two putative $\beta$ Glu isoforms are located in the endosperm and in the embryo, with a predominance of the $43 \mathrm{kDa}$ bands in the embryo. Taken together, these findings in four species suggested that the accumulation of ABA-sensitive $\beta$ Glu I in the endosperm after testa rupture, but prior to endosperm rupture, appears to be a common phenomenon during the germination of Cestroideaetype seeds.

\section{$\beta$ Glu and Chn are co-induced in the roots of Solanaceous seedlings as a post-germination event}

$\beta$ Glu I induction in germinating tobacco seeds prior to endosperm rupture is confined to the micropylar endosperm and is absent from the lateral endosperm and the embryo (Fig. 2A; Leubner-Metzger et al., 1995). When we extended our studies to germinated tobacco seedlings at $90 \mathrm{~h}$ and $150 \mathrm{~h}$, we found an additional, post-germination induction phase of $\beta$ Glu I that is localized in the root, but not appreciably in the shoot of the seedlings (Fig. 2A; Table 2). Chn is not induced prior to the completion of endosperm rupture of N. tabacum (Fig. 2B, C; Leubner-Metzger et al., 1995) and N. sylvestris (data not shown). However, in germinated tobacco seedlings at $90 \mathrm{~h}$ and $150 \mathrm{~h}$, the mRNA and the $32 \mathrm{kDa}$ and $34 \mathrm{kDa}$ antigens of Chn I are detected (Fig. 2B, C). As for the $\beta$ Glu I, Chn I accumulation is also mainly localized to the root of the tobacco seedlings (Table 2). In contrast to $\beta$ Glu I, which is transcriptionally down-regulated by $\mathrm{ABA}$ in seeds and in vegetative tissues, Chn I expression in vegetative tissues is not down-regulated by $\mathrm{ABA}$ (Leubner-Metzger et al., 1995; Rezzonico et al., 1998). This was also the case in ABA-treated tobacco seeds and, since ABA delays endosperm rupture, this leads to the finding that $\mathrm{Chn} \mathrm{I}$ accumulates prior to endosperm rupture in ABA-treated seeds (Fig. 2B, C). This is in contrast to seeds imbibed in medium without ABA added, and the Chn I levels found in $150 \mathrm{~h}$ seedlings were similar to those found in $150 \mathrm{~h}$ seeds treated with ABA (Fig. 2B). In contrast to tobacco, $\mathrm{Chn} \mathrm{I}$ is also induced prior to germination in tomato seeds in medium lacking $\mathrm{ABA}(\mathrm{Wu}$ et al., 2000). As in tobacco, $\beta$ Glu and Chn activity accumulations are associated with the root, but appreciably less with the shoot, of tomato and pepper seedlings (Table 2). Thus, a post-germination coinduction of $\beta$ Glu and $\mathrm{Chn}$ in the root of seedlings seems to be a general phenomenon in both subgroups of the Solanaceae.

\section{Temporal and spatial pattern of $\beta$ Glu and Chn accumulation are distinct among Solanoideae-type seeds}

Tomato, Physalis peruviana and Capsicum annuum belong to the Solanoideae subgroup of Solanaceae and are characterized by flattened, discoid seeds with curved embryos, and the micropylar endosperm and testa layers of pepper and tomato form a cap-like structure (Watkins and Cantliffe, 1983; Watkins et al., 1985; Judd et al., 1999). $\beta$ Glu I and Chn I are both coexpressed in the micropylar endosperm of tomato prior to radicle emergence ( $\mathrm{Wu}$ et al., 2000). Using highly sensitive radiometric assays with $\left[{ }^{3} \mathrm{H}\right]$ laminarin and $\left[{ }^{3} \mathrm{H}\right]$ chitin as substrates, respectively, similar contents and kinetics of specific $\beta$ Glu and Chn activities were obtained in tomato seeds. Figure 3 shows that by using the same highly sensitive radiometric assays, only the accumulation of $\beta$ Glu activity, but not of Chn activity, was detected in germinating pepper seeds. The onset of radicle protrusion of imbibed pepper seed populations was not detected in the $72 \mathrm{~h}$ samples, but started slightly later. As in tomato, $\beta$ Glu activity accumulates in the micropylar cap of pepper seeds prior to its rupture by the protruding radicle and germination is inhibited by ABA (Fig. 3B). In contrast to tomato, where $\beta$ Glu accumulation is confined to the micropylar 

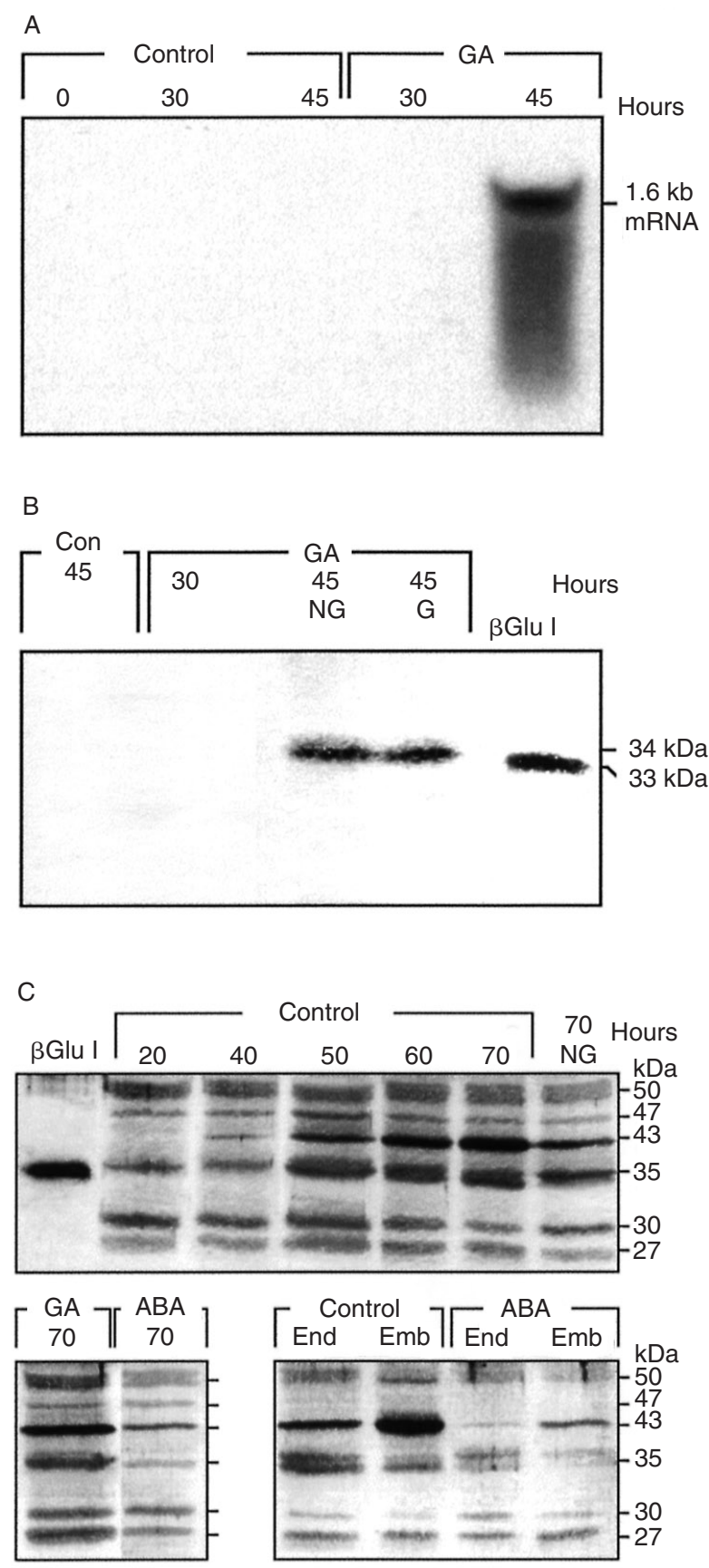

Figure 1. Hormone-regulated accumulation of tobacco $\beta$ Glu I-related mRNAs and antigens during the germination of Cestroideae-type Solanaceae seeds. (A) RNA-blot hybridization of total RNA ( $25 \mu \mathrm{g} /$ lane) prepared from Nicotiana plumbaginifolia seeds imbibed in continuous light either in the absence (Control) or presence of $10 \mu \mathrm{M}$ GA 4 (GA); only GA-treated seeds germinate. The RNA-blot was hybridized with a cDNA probe for tobacco $\beta G l u$ I. (B) Immunoblot analysis of N. plumbaginifolia seed extracts $(80 \mu \mathrm{g}$ protein/lane) probed with the rabbit anti-tobacco $\beta \mathrm{Glu} \mathrm{I}$ antibody. $\mathrm{G}=$ germinated seeds only; $\mathrm{NG}=$ ungerminated seeds only. $\beta$ Glu $\mathrm{I}=10 \mathrm{ng}$ of the authentic $33 \mathrm{kDa}$ tobacco enzyme. No signals were obtained in control blots with rabbit anti-tobacco Chn I antibody or with rabbit pre-immune serum. (C) Immunoblot analysis of Petunia hybrida seed extracts using the anti-tobacco $\beta$ Glu I antibody; GA $=10 \mu \mathrm{M} \mathrm{GA} ; \mathrm{ABA}=10 \mu \mathrm{M}$ ABA, End = endosperm, Emb $=$ embryo; analysis as described in (B) with the difference that $50 \mu \mathrm{g}$ protein/lane (entire seeds) and $30 \mu \mathrm{g}$ protein/lane (End, Emb) were applied. 
A
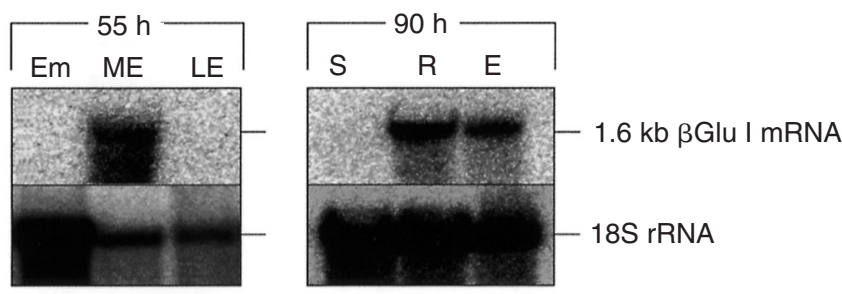

\section{B}
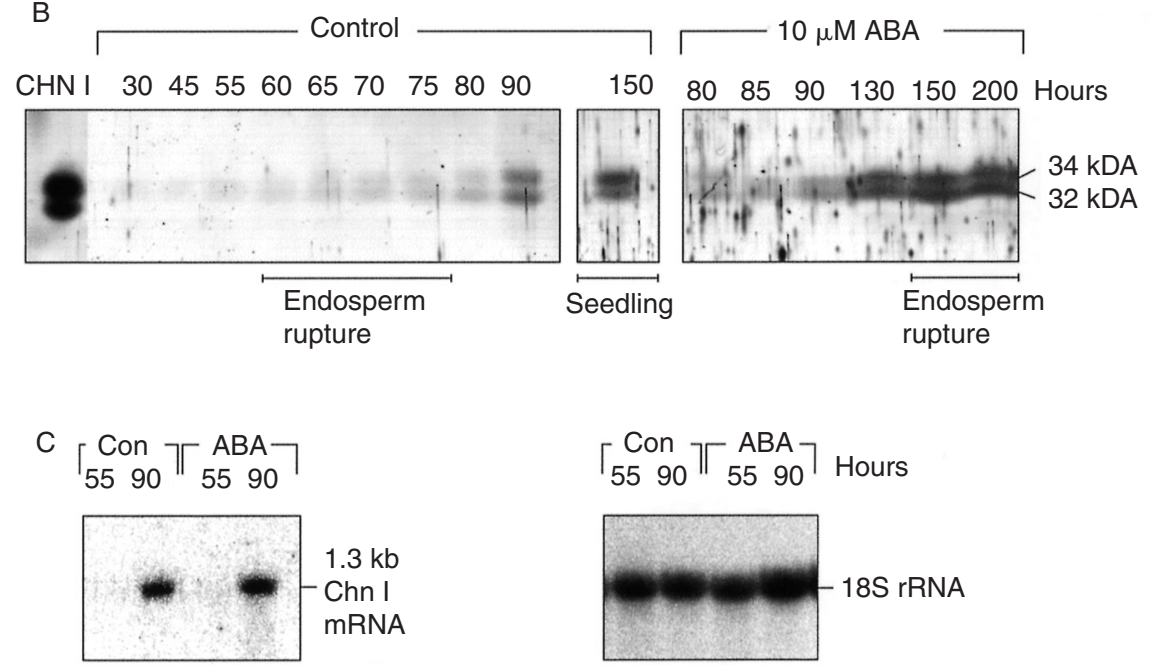

Figure 2. Tissue specificity and regulation by abscisic acid (ABA) of $\beta$ Glu I and Chn I in imbibed seeds and in seedlings of Nicotiana tabacum. (A) RNA-blot hybridization of total RNA ( $25 \mu \mathrm{g} /$ lane) prepared from seeds prior to endosperm rupture $(55 \mathrm{~h})$ during imbibition in continuous light and from $90 \mathrm{~h}$ seedlings. The RNA-blot was hybridized with a cDNA probe for tobacco $\beta$ Glu I, and a probe for 18S rRNA was used as a loading standard. Em = embryo; ME = micropylar endosperm; LE = lateral endosperm; $\mathrm{S}=$ shoot; $\mathrm{R}=$ root; $\mathrm{E}=90 \mathrm{~h}$ endosperm remnant. (B) Immunoblot analysis of seed and seedling extracts (80 $\mu \mathrm{g}$ protein/lane) probed with the rabbit anti-tobacco Chn I antibody. Seeds and seedlings were imbibed in continuous light either in the absence (Control) or presence of $10 \mu \mathrm{M} \mathrm{ABA}$. CHN I = $10 \mathrm{ng}$ of the authentic $32 \mathrm{kDa}$ and $34 \mathrm{kDa}$ tobacco enzymes. (C) RNA-blot hybridization of total RNA prepared from seeds and seedlings incubated in medium without (Con) or with $10 \mu \mathrm{M}$ ABA added (ABA). The RNA-blot was hybridized with probes for tobacco Chn I and 18S rRNA as described in (A).

Table 2. Tissue-specificity of $\beta$-1,3-glucanase ( $\beta \mathrm{Glu}$ ) and chitinase (Chn) enzyme activity in Solanaceous seedlings

\begin{tabular}{|c|c|c|c|c|c|c|}
\hline Species ${ }^{b}$ & \multicolumn{3}{|c|}{$\beta G^{\prime} u^{a}$} & \multicolumn{3}{|c|}{$\mathrm{Chn}^{\mathrm{a}}$} \\
\hline Tomato & $1.0 \pm 0.5$ & $0.1 \pm 0.0$ & 10 & - & - & - \\
\hline Tobacco & $11.7 \pm 1.1$ & $2.0 \pm 0.6$ & 6 & $31.1 \pm 5.5$ & $6.8 \pm 2.6$ & 5 \\
\hline
\end{tabular}

a Mean values \pm SE of enzyme activities in pkat $/ \mu \mathrm{g}$ protein of four protein samples, each from 10-15 seedling tissues.

b Seedlings from germinated seeds incubated for $150 \mathrm{~h}$ (tobacco) or $160 \mathrm{~h}$ (pepper, tomato) in continuous light at $24^{\circ} \mathrm{C}$.

${ }^{\mathrm{c}}$ Ratio between the specific enzyme activities of the seedling root and shoot tissues.

endosperm, $\beta$ Glu activity also accumulated in the embryo (Fig. 3A) and the rest of the pepper seed (Fig. $3 C)$. The $\beta$ Glu activity accumulation in all three compartments was inhibited by ABA (Fig. 3). $\beta$ Glu activity also accumulated in imbibed seeds of $P$. peruviana and the enzyme activity accumulation was only partially inhibited by ABA (Table 1$)$.
To further investigate the tissue- and speciesspecific accumulation of $\beta$ Glu isoforms, we performed immunoblot analyses with the different pepper seed tissues. The rabbit anti-tobacco $\beta$ Glu I antibody, which is known to also detect the $35 \mathrm{kDa}$ tomato $\beta$ Glu I in the micropylar endosperm (Wu et al., 2000), detected a distinct temporal and spatial pattern 


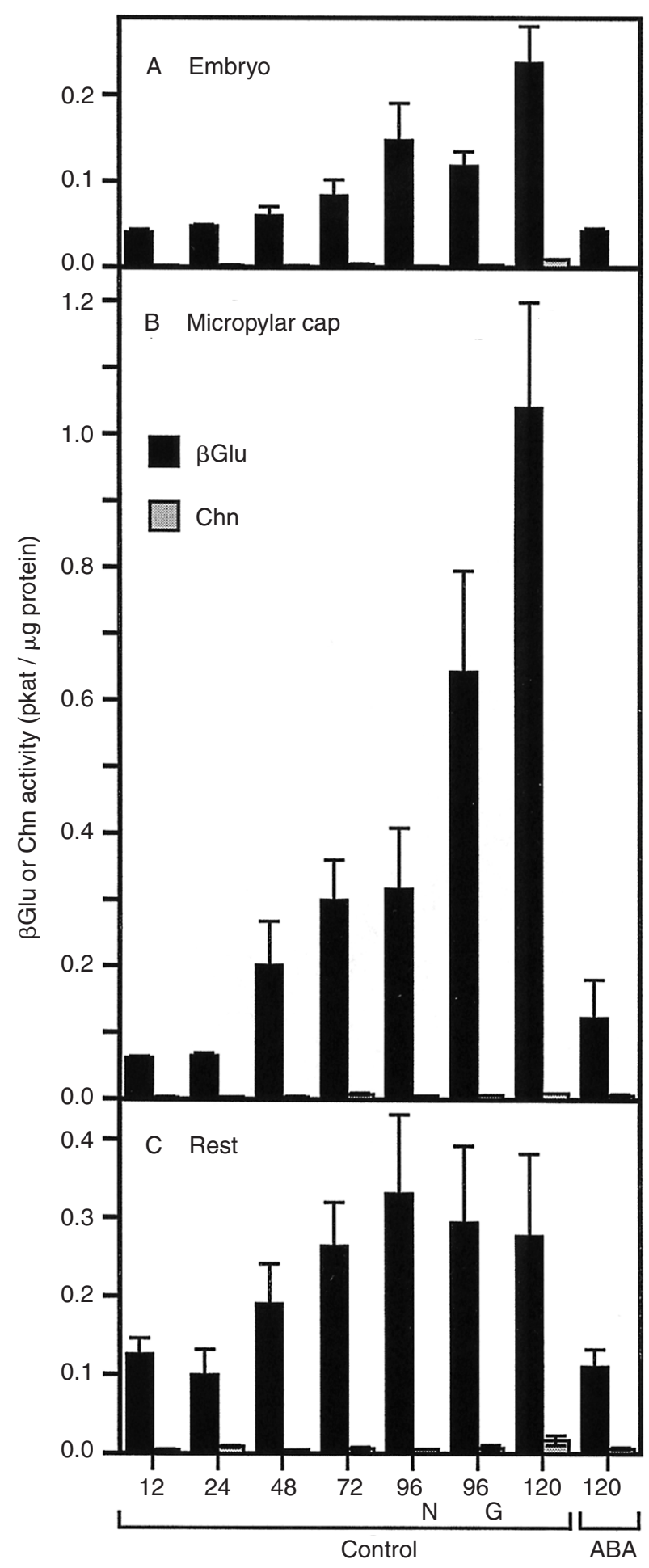

Figure 3. Tissue specificity and regulation by ABA of $\beta$ Glu and Chn activities during the seed germination of Capsicum annuum, measured in (A) embryo, (B) micropylar cap and (C) the rest of the seed. Populations of 20 seeds were imbibed in continuous light, either in the absence (Control) or presence of $100 \mu \mathrm{M}$ ABA (ABA), and seeds were dissected at the times indicated. Specific $\beta$ Glu and Chn activities are expressed in pkat/ $\mu$ g protein. Mean values \pm SE are presented from four to ten replicate samples at each time point. Radicle protrusion of imbibed pepper seeds: $0 \%$ until $72 \mathrm{~h}, 11.6 \%$ at $96 \mathrm{~h}, 100 \%$ at $120 \mathrm{~h}(\mathrm{Control})$ and $0 \%$ for ABA-treated seeds at $120 \mathrm{~h}$. At $96 \mathrm{~h}$ non-germinated $(\mathrm{N})$ and germinated $(\mathrm{G})$ seeds were measured separately. 
of immunoreactive bands in the different seed compartments and in seedlings (Fig. 4). A major, $c$. $39.5 \mathrm{kDa}$ band increased in intensity in the embryo prior to and during endosperm rupture, but was not detected in the micropylar cap prior to endosperm rupture or in the rest of the seed. The $39.5 \mathrm{kDa}$ band was also present in the micropylar cap of $120 \mathrm{~h}$ germinated seeds, but not in ABA-treated ungerminated seeds. The appearance of the $39.5 \mathrm{kDa}$ band in the embryo was inhibited by ABA (Fig. 4A), which also inhibited $\beta$ Glu activity accumulation (Fig. $3 \mathrm{~A})$. The $39.5 \mathrm{kDa}$ band was the only band detected in seedling shoots and was absent from seedling roots (Fig. 4A). Additional bands, c. $27 \mathrm{kDa}$ and $31 \mathrm{kDa}$ in size, were detected at roughly constitutive levels in all seed tissues (Fig. 4). The $27 \mathrm{kDa}$ band was especially strong in the embryo, but was absent from seedlings. Roughly constitutive levels of a c. $24 \mathrm{kDa}$ band were found in the endosperm, but not in embryos or seedlings. Treatment with ABA did not affect the levels of the 24,27 and $31 \mathrm{kDa}$ bands, but the transition from the embryo state to the seedling state was associated with the disappearance of these bands. A c. $33 \mathrm{kDa}$ band was detected in seedling roots. Thus, a complex tissue-specific pattern of putative $\beta$ Glu was detected in imbibed seeds and in seedlings of pepper. In contrast to pepper, the rabbit anti-tobacco $\beta$ Glu I antibody did not detect any antigen in protein extracts from seed extracts of $P$. peruviana. Finally, in agreement with the finding that Chn activity did not accumulate during pepper seed germination, the rabbit anti-tobacco Chn I antibody did not detect immunoreactive bands in imbibed pepper seeds (data not shown); but it did detect Chn I in tomato seeds (Wu et al., 2000).

\section{Discussion}

Two developmentally regulated sites of $\beta$ Glu induction seem to be common among Solanaceous species: (1) $\beta G l u$ accumulation in imbibed seeds prior to endosperm rupture, and (2) $\beta$ Glu accumulation in roots of young seedlings as a post-germination event. Whereas co-induction of Glu and Chn in seedling roots appears to be a common phenomenon, significant differences exist among Solanaceous species during seed germination. The various $\beta G l u$ isoforms of tobacco, tomato, potato, pepper and other species have been classified into at least three structural classes that differ by a minimum of $40-50 \%$ in amino acid sequence identity of the mature proteins (Meins et al., 1992; Simmons, 1994; LeubnerMetzger and Meins, 1999). The endo-type class I enzymes ( $\beta$ Glu I) include the highly homologous $33 \mathrm{kDa}$ isoforms of $N$. tabacum and $N$. sylvestris (Sperisen et al., 1991; Neuhaus et al., 1992), the $34 \mathrm{kDa}$ isoforms of N. plumbaginifolia (Gn2 and Gn1 share 98\% and $76 \%$ amino acid sequence identity with tobacco BGlu I, respectively; Castresana et al., 1990; Gheysen et al., 1990), the $35 \mathrm{kDa}$ tomato isoform Glu B (c. $90 \%$ amino acid sequence identity with tobacco $\beta$ Glu I; Van Kan et al., 1992; Wu et al., 2000), and the $\beta$ Glu I of pepper exhibits a similarly high degree of sequence identity (Kim and Hwang, 1997; Jung and Hwang, 2000b; Pflieger et al., 2001). These $\beta$ Glu I isoforms are usually basic, intracellular proteins, but there is strong evidence that they can also be secreted (Simmons, 1994; Leubner-Metzger and Meins, 1999). In contrast to $\beta$ Glu I, the class II and III $\beta$ Glu are secreted into the apoplast. Characteristic differences between class I and II $\beta$ Glu genes are also evident at the level of gene regulation by ethylene, ABA, salicylic acid, pathogens and other factors. BGlu I gene expression is induced transcriptionally in vegetative tissues and in seeds by ethylene, and down-regulated by ABA (e.g. Leubner-Metzger et al., 1995; Rezzonico et al., 1998; Jung and Hwang, 2000b; Wu et al., 2000). As for $\beta \mathrm{Glu}$, similar structural classes exist for the Chn isoforms, and $\beta$ Glu I and Chn I are often co-induced, e.g. in leaves by ethylene or pathogens. In contrast to $\beta$ Glu I, Chn I is not transcriptionally down-regulated by $\mathrm{ABA}$ and does not accumulate in the micropylar endosperm of germinating tobacco seeds (Leubner-Metzger et al., 1995), but does accumulate in the micropylar endosperm of germinating tomato seeds ( $\mathrm{Wu}$ et al., 2000). The present study shows that Cestroideae- and Solanoideae-type seeds not only differ in their morphology (Judd et al., 1999), but that they also exhibit common and distinct aspects with regard to the hormonal and developmental regulation of $\beta \mathrm{Glu}$ and Chn.

\section{$\beta$ Glu induction in the endosperm, and endosperm rupture but not testa rupture, are inhibited by $A B A$ in Cestroideae-type seeds}

Our most intriguing findings with Cestroideae-type seeds (three Nicotiana species and petunia) are the common distinction between testa rupture and endosperm rupture, and that ABA-sensitive $\beta \mathrm{Glu}$ accumulation occurs prior to endosperm rupture, but after testa rupture. As in tobacco (Arcila and Mohapatra, 1983; Leubner-Metzger et al., 1995), testa rupture and endosperm rupture of $N$. sylvestris, $N$. plumbaginifolia and petunia are distinct and sequential events. As in tobacco, ABA does not appreciably inhibit testa rupture, but inhibits $\beta$ Glu accumulation in the endosperm and endosperm rupture (Table 3 ). GA treatment is required to release dormancy and induce $\beta$ Glu accumulation and germination of $N$. plumbaginifolia seeds imbibed in the light and $N$. sylvestris seeds imbibed in darkness. These results are 


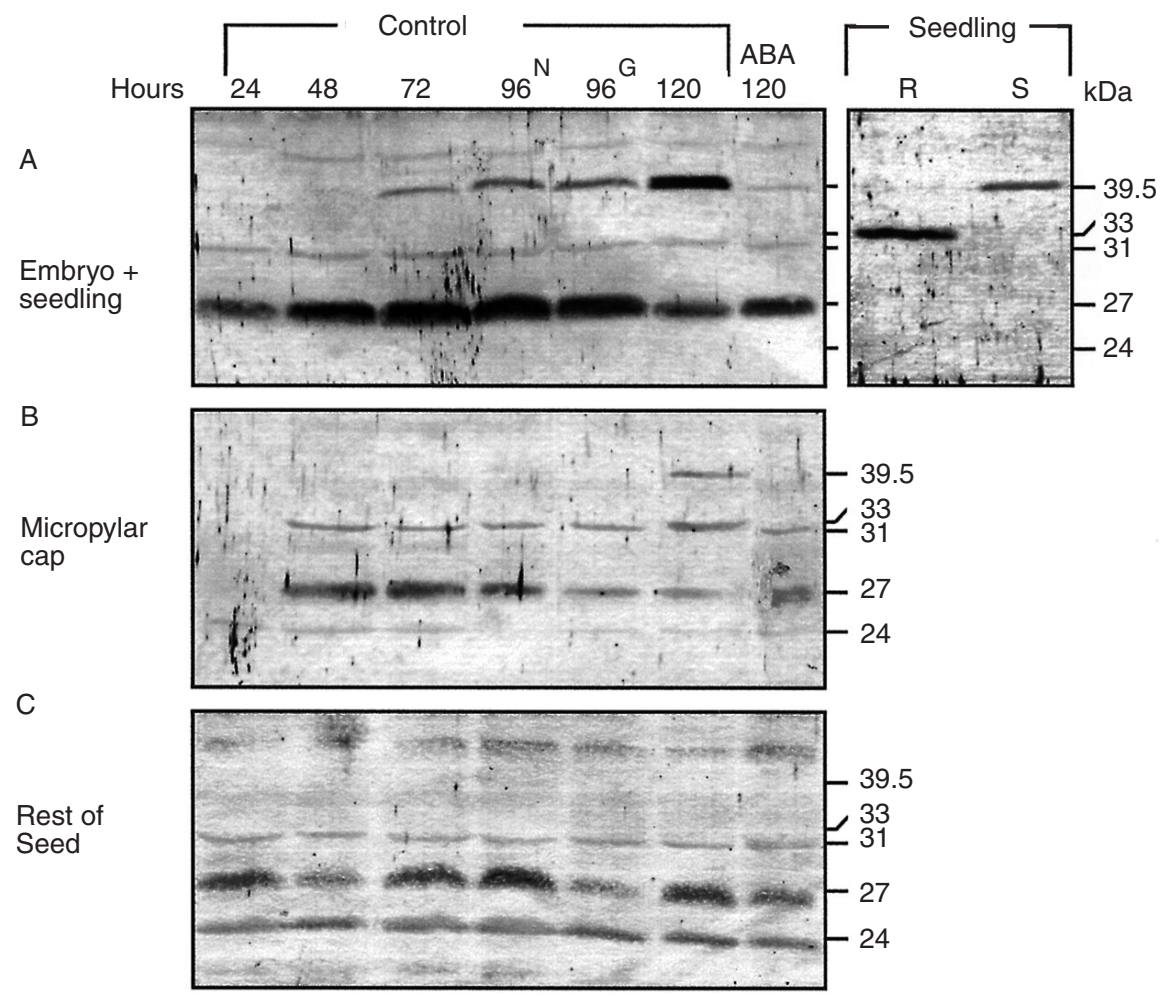

Figure 4. Tissue specificity and regulation by ABA of $\beta$ Glu antigens during germination of Capsicum annuum seeds, in (A) embryo and 160 h-seedling, (B) micropylar cap and (C) the rest of the seed. Immunoblot analysis of seed and seedling extracts (40 $\mu \mathrm{g}$ protein/lane) probed with the rabbit anti-tobacco $\beta$ Glu I antibody, which recognizes all known tobacco $\beta$-1,3-glucanases and is also known to cross-react with tomato BGlu I (Neuhaus et al., 1992; Beffa et al., 1993; Petruzzelli et al., 1999; Wu et al., 2000; Kunz et al., 2001). No signals were obtained in control blots with rabbit anti-tobacco Chn I antibody or with rabbit pre-immune serum. Extracts and germination are as described in Fig. 3. $\mathrm{R}=$ root, $\mathrm{S}=$ shoot.

in agreement with the roles of $\mathrm{ABA}$ and $\mathrm{GA}$ in regulating dormancy and germination of Nicotiana species (e.g. Leubner-Metzger et al., 1996; Frey et al., 1999; Grappin et al., 2000; Leubner-Metzger, 2001) and of petunia (Sink, 1984; Girard, 1990). The highly homologous $34 \mathrm{kDa}$ and $33 \mathrm{kDa} \beta$ Glu I isoforms of $N$. plumbaginifolia (Castresana et al., 1990; Gheysen et al., 1990) and N. sylvestris (Sperisen et al., 1991; Neuhaus et al., 1992), respectively, accumulate after testa rupture, but prior to endosperm rupture. As in tobacco, germination and $\beta$ Glu I accumulation seem to depend on the light/GA pathway and are inhibited by ABA (Leubner-Metzger et al., 1996; LeubnerMetzger, 2001). No sequence information is available for petunia $\beta$ Glu isoforms, but the anti-tobacco $\beta$ Glu I antibody detected several constitutively expressed immunoreactive bands, as well as two immunoreactive bands, $35 \mathrm{kDa}$ and $43 \mathrm{kDa}$ in size, that exhibit ABA-inhibited regulation. In contrast to Nicotiana seeds, enzyme activity and antigen accumulation in petunia are present in both endosperm and embryo. It seems likely, but not proven, that the $35 \mathrm{kDa}$ band that accumulates in association with endosperm rupture is a petunia $\beta G l u$ I. Taken together, these findings suggest that the accumulation of $\beta$ Glu I prior to endosperm rupture and the regulation of $\beta$ Glu I expression by light/GA and $\mathrm{ABA}$ could be an evolutionarily conserved developmental event in Cestroideae-type seeds (Leubner-Metzger, 2003).

\section{Distinct expression pattern of $\beta$ Glu and Chn isoforms in germinating Solanaceous seeds}

ABA also inhibits endosperm rupture of Solanoideaetype seeds such as tomato (Hilhorst, 1995; Toorop et al., 2000; Wu et al., 2000) and pepper, but not $P$. peruviana (this study). As in Cestroideae-type seeds, $\beta$ Glu also accumulates prior to endosperm rupture of tomato, pepper and Physalis seeds (Table 3). As in tobacco, $\beta$ Glu accumulation in the micropylar endosperm of tomato and pepper is inhibited by ABA. In contrast to tobacco and tomato, $\beta$ Glu accumulation in pepper and petunia seeds is not 


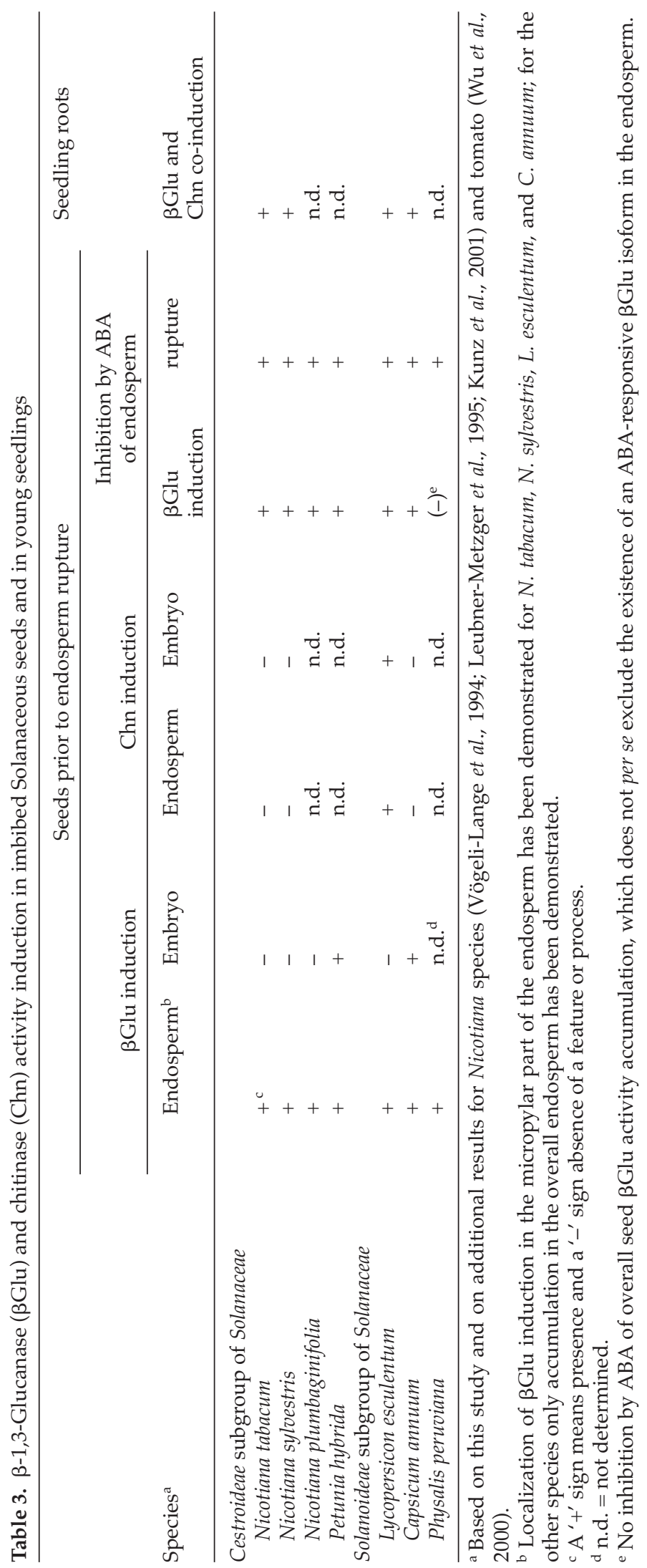


confined exclusively to the micropylar tissue, but also accumulates in other seed parts, especially in the embryo. At least ten basic and acidic $\beta$ Glu isoforms have been described in healthy and infected vegetative pepper tissues, corresponding to sizes of 25, 27, 29, 34, and $36 \mathrm{kDa}$ in denaturing gels (e.g. Kim and Hwang, 1994, 1997; Egea et al., 1999). The limited sequence information on pepper available in databases includes a $39.3 \mathrm{kDa}$ ethylene-inducible BGlu I (Jung and Hwang, 2000a, b; Pflieger et al., 2001). Using the anti-tobacco $\beta$ Glu I antibody, we detected a major c. $39.5 \mathrm{kDa}$ band in the embryo prior to and during germination, and in seedling shoots. This band is not present during early imbibition, is not induced in the micropylar cap prior to endosperm rupture, nor in the rest of the seed or in seedling roots. Its appearance is inhibited by ABA and it corresponds in size to the ethylene-inducible $39.3 \mathrm{kDa} \beta$ Glu I described by Jung and Hwang (2000b). The anti-tobacco $\beta$ Glu I antibody also detected several other immunoreactive bands that were 24,27 and $31 \mathrm{kDa}$ in size, roughly constitutive and not affected by ABA. The nature of these bands is not known, and the limited sequence information, together with expected cultivar differences, does not allow an unambiguous identification of these isoforms. ABA-sensitive $\beta$ Glu activity accumulation was especially strong in the micropylar endosperm of pepper seeds, but none of the detected bands correlated with this activity pattern. Thus, a serologically distinct ABA-sensitive $\beta$ Glu isoform must account for the $\beta G l u$ accumulation in the micropylar cap of imbibed pepper seeds. The antitobacco $\beta$ Glu I antibody also detected a c. $33 \mathrm{kDa}$ band, but only in seedling roots. Considering the known serological relatedness of the tobacco and tomato $\beta$ Glu I with the $34 \mathrm{kDa}$ pepper $\beta$ Glu I (e.g. Kim and Hwang, 1997; Wu et al., 2000), we propose that this is a pepper $\beta$ Glu I, probably the basic $34 \mathrm{kDa}$ isoform described by Kim and Hwang (1997). The tissue-specific and ABA-regulated differences in band patterns suggest that several distinct $\beta G l u$ isoforms account for the $\beta$ Glu activities of pepper and petunia. ABA did not inhibit overall $\beta$ Glu activity accumulation in seeds of $P$. peruviana; however, it is still a reasonable, but unproven, hypothesis that several distinct $\beta$ Glus accumulate and that, among them, are ABA-sensitive and insensitive isoforms. The finding that the antitobacco $\beta$ Glu I antibody did not detect any signals in seed extracts of $P$. peruviana is a complication for testing this hypothesis. Prior to endosperm rupture, BGlu I expression in Nicotiana and tomato seeds is confined to the micropylar endosperm, whereas in pepper and petunia seeds, distinct isoforms confer $\beta$ Glu activity accumulation in several tissues (this study; Leubner-Metzger et al., 1995; Wu et al., 2000).
Chn is not expressed in Nicotiana and pepper seeds prior to endosperm rupture, but Chn I is expressed in the micropylar endosperm of tomato (Table 3). Interestingly, jasmonates or wounding induce Chn I expression in the micropylar endosperm of tomato (Wu and Bradford, 2002), but do not induce $\beta$ Glu I in tomato (Wu and Bradford, 2002) or tobacco seeds (Leubner-Metzger, personal communication). Thus, $\beta$ Glu I and Chn I induction in the micropylar endosperm may be regulated by distinct signalling pathways. Therefore, we propose that signalling of ABA-sensitive $\beta G l u$ induction in the micropylar endosperm is an evolutionarily conserved pathway that is widespread in Solanaceous seeds and serves a developmental function during endosperm rupture. This is in agreement with direct evidence obtained by sense transformation of tobacco, which showed that $\beta$ Glu I contributes to endosperm rupture (LeubnerMetzger and Meins, 2000). In contrast, $\beta$ Glu expression in other seed tissues and Chn expression in seeds occur only in some Solanaceous species, is regulated by distinct and diverse pathways, and therefore might serve different developmental or pathogenesis-related functions ( $\mathrm{Wu}$ and Bradford, 2002; Leubner-Metzger, 2003).

\section{Evolutionarily conserved induction of $\beta$ Glu in seedling roots of endospermic and non- endospermic species}

We found that a post-germination induction of $\beta$ Glu and Chn occurred mainly in the roots of young seedlings and appears to be an additional evolutionarily conserved site of $\beta$ Glu I induction (Table 3). In contrast to the micropylar endosperm, $\beta \mathrm{Glu} I$ and $\mathrm{Chn}$ I are co-induced in the roots of young tobacco seedlings. $\beta$ Glu and $\mathrm{Chn}$ are also co-induced in the roots of tomato and pepper seedlings, and appear to be the class I isoforms. $\beta$ Glu I is also induced in seedlings of $N$. sylvestris, and increased $\beta$ Glu I and Chn I levels are present in older seedlings of this species (Vögeli-Lange et al., 1994; Kunz et al., 1996, 2001). BGlu I and Chn I accumulate at high concentrations in the roots and in lower leaves of mature, healthy Solanaceous plants (Van de Rhee et al., 1993; Beerhues and Kombrink, 1994; Vögeli-Lange et al., 1994; Leubner-Metzger and Meins, 1999). The establishment of this gradient of $\beta$ Glu I and Chn I expression is regulated by ethylene. In agreement with these findings, endogenous ethylene also induces the accumulation of a $\beta$ Glu I in the root, but not the shoot, of pea seedlings directly after germination (Petruzzelli et al., 1999, 2000, 2003). Within the pea root, ethylene responsiveness and $\beta$ Glu I accumulation are localized to the elongation and differentiation zones where the root hairs form. In contrast to Solanaceous seeds, pea seeds are non- 
dormant and non-endospermic. This supports the view that the post-germination induction of $\beta G l u ~ I$ (and possibly also Chn I) is widespread among dicot seedlings and represents an evolutionarily conserved event (Leubner-Metzger, 2003).

\section{Acknowledgements}

We thank Waltraud Schmidt-Puchta for kindly providing plasmids and Sjoerd van Eeden (Friedrich Miescher Institute, Basel, Switzerland) for care of plants. This research is supported by a grant from the Deutsche Forschungsgemeinschaft (LE 720/3) to G.L.-M., which is gratefully acknowledged.

\section{References}

Arcila, J. and Mohapatra, S.C. (1983) Development of tobacco seedling. 2. Morphogenesis during radicle protrusion. Tobacco Science 27, 35-40.

Beerhues, L. and Kombrink, E. (1994) Primary structure and expression of mRNAs encoding basic chitinase and 1,3- $\beta$-glucanase in potato. Plant Molecular Biology 24, 353-367.

Beffa, R.S., Neuhaus, J.-M. and Meins, F. (1993) Physiological compensation in antisense transformants: Specific induction of an 'ersatz' glucan endo-1,3- $\beta$ glucosidase in plants infected with necrotizing viruses. Proceedings of the National Academy of Sciences, USA 90, 8792-8796.

Bewley, J.D. (1997a) Breaking down the walls - a role for endo- $\beta$-mannanase in release from seed dormancy? Trends in Plant Science 2, 464-469.

Bewley, J.D. (1997b) Seed germination and dormancy. Plant Cell 9, 1055-1066.

Bihlmeier, M. (1927) Der Einfluss der Vorquellung und der Samenschale auf die Keimung lichtgeförderter Samen. Jahrbücher für Wissenschaftliche Botanik 67, 702-732.

Castresana, C., De Carvalho, F., Gheysen, G., Habets, M., Inze, D. and van Montagu, M. (1990) Tissue-specific and pathogen-induced regulation of a Nicotiana plumbaginifolia $\beta-1,3-$ glucanase gene. Plant Cell 2, 1131-1143.

Egea, C., Dickinson, M.J., Candela, M. and Candela, E.M. (1999) $\beta-1,3-G l u c a n a s e$ isoenzymes and genes in resistant and susceptible pepper (Capsicum annuum) cultivars infected with Phytophthora capsici. Physiologia Plantarum 107, 312-318.

Frey, A., Audran, C., Marin, E., Sotta, B. and Marion-Poll, A. (1999) Engineering seed dormancy by the modification of zeaxanthin epoxidase gene expression. Plant Molecular Biology 39, 1267-1274.

Gheysen, G., Inze, D., Soetaert, P., van Montagu, M. and Castresana, C. (1990) Sequence of a Nicotiana plumbaginifolia $\beta$-1,3-glucanase gene encoding a vacuolar isoform. Nucleic Acids Research 18, 6685.

Girard, J. (1990) Study of the inheritance of seed primary dormancy and the ability to enter secondary dormancy in Petunia: influence of temperature, light and gibberellic acid on dormancy. Plant Cell and Environment 13, 827-832.

Grappin, P., Bouinot, D., Sotta, B., Miginiac, E. and Jullien, M. (2000) Control of seed dormancy in Nicotiana plumbaginifolia: post-imbibition abscisic acid synthesis imposes dormancy maintenance. Planta 210, 279-285.

Hilhorst, H.W.M. (1995) A critical update on seed dormancy. I. Primary dormancy. Seed Science Research 5, $61-73$.

Hilhorst, H.W.M. and Downie, B. (1996) Primary dormancy in tomato (Lycopersicon esculentum cv. Moneymaker): Studies with the sitiens mutant. Journal of Experimental Botany 47, 89-97.

Judd, W.S., Campbell, C.S., Kellog, E.A. and Stevens, P.F. (1999) Plant systematics: a phylogenetic approach. Sunderland, Massachusetts, USA, Sinauer Associates, Inc.

Jung, H.W. and Hwang, B.K. (2000a) Isolation, partial sequencing, and expression of pathogenesis-related cDNA genes from pepper leaves infected by Xanthomonas campestris pv. vesicatoria. Molecular Plant-Microbe Interactions 13, 136-142.

Jung, H.W. and Hwang, B.K. (2000b) Pepper gene encoding a basic $\beta$-1,3-glucanase is differentially expressed in pepper tissues upon pathogen infection and ethephon or methyl jasmonate treatment. Plant Science 159, 97-106.

Kim, Y.J. and Hwang, B.K. (1994) Differential accumulation of $\beta$-1,3-glucanase and chitinase isoforms in pepper stems infected by compatible and incompatible isolates of Phytophthora capsici. Physiological and Molecular Plant Pathology 45, 195-209.

Kim, Y.J. and Hwang, B.K. (1997) Isolation of a basic 34 kiloDalton $\beta$-1,3-glucanase with inhibitory activity against Phytophthora capsici from pepper stems. Physiological and Molecular Plant Pathology 50, 103-115.

Kincaid, R.R. (1935) The effects of certain environmental factors on the germination of Florida cigar-wrapper tobacco seeds. Technical Bulletin of the University of Florida Agricultural Experimental Station 277, 5-47.

Koornneef, M., Bentsink, L. and Hilhorst, H. (2002) Seed dormancy and germination. Current Opinion in Plant Biology 5, 33-36.

Kunz, C., Schöb, H., Stam, M., Kooter, J.M. and Meins, F. (1996) Developmentally regulated silencing and reactivation of tobacco chitinase transgene expression. Plant Journal 10, 437-450.

Kunz, C., Schöb, H., Leubner-Metzger, G., Glazov, E. and Meins, F. (2001) $\beta-1,3-G l u c a n a s e$ and chitinase transgenes in hybrids show distinctive and independent patterns of posttranscriptional gene silencing. Planta 212, 243-249.

Leubner-Metzger, G. (2001) Brassinosteroids and gibberellins promote tobacco seed germination by distinct pathways. Planta 213, 758-763.

Leubner-Metzger, G. (2002) Seed after-ripening and overexpression of class I $\beta$-1,3-glucanase confer maternal effects on tobacco testa rupture and dormancy release. Planta 215, 959-968.

Leubner-Metzger, G. (2003) Functions of $\beta-1,3$-glucanases during seed germination, dormancy release and afterripening. Seed Science Research 13, 17-34.

Leubner-Metzger, G. and Meins, F. (1999) Functions and regulation of plant $\beta-1,3$-glucanases (PR-2). pp. 49-76 in 
Datta, S.K.; Muthukrishnan, S. (Eds) Pathogenesis-related proteins in plants. Boca Raton, Florida, CRC Press.

Leubner-Metzger, G. and Meins, F. (2000) Sense transformation reveals a novel role for class I $\beta-1,3-$ glucanase in tobacco seed germination. Plant Journal 23, 215-221.

Leubner-Metzger, G., Fründt, C., Vögeli-Lange, R. and Meins, F. (1995) Class I $\beta-1,3$-glucanase in the endosperm of tobacco during germination. Plant Physiology 109, 751-759.

Leubner-Metzger, G., Fründt, C. and Meins, F. (1996) Effects of gibberellins, darkness and osmotica on endosperm rupture and class I $\beta$-1,3-glucanase induction in tobacco seed germination. Planta 199, 282-288.

Leubner-Metzger, G., Petruzzelli, L., Waldvogel, R., Vögeli-Lange, R. and Meins, F. (1998) Ethyleneresponsive element binding protein (EREBP) expression and the transcriptional regulation of class I $\beta-1,3-$ glucanase during tobacco seed germination. Plant Molecular Biology 38, 785-795.

Liptay, A. and Schopfer, P. (1983) Effect of water stress, seed coat restraint, and abscisic acid upon different germination capabilities of two tomato lines at low temperature. Plant Physiology 73, 935-938.

Meins, F., Neuhaus, J.-M., Sperisen, C. and Ryals, J. (1992) The primary structure of plant pathogenesis-related glucanohydrolases and their genes. pp. 245-282 in Boller, T.; Meins, F. (Eds) Genes involved in plant defense. Vienna, Springer-Verlag.

Neuhaus, J.M., Flores, S., Keefe, D., Ahl-Goy, P. and Meins, F. (1992) The function of vacuolar $\beta-1,3-$ glucanase investigated by antisense transformation. Susceptibility of transgenic Nicotiana sylvestris plants to Cercospora nicotianae infection. Plant Molecular Biology 19, 803-813.

Nonogaki, H., Gee, O.H. and Bradford, K.J. (2000) A germination-specific endo- $\beta$-mannanase gene is expressed in the micropylar endosperm cap of tomato seeds. Plant Physiology 123, 1235-1245.

Petruzzelli, L., Kunz, C., Waldvogel, R., Meins, F. and Leubner-Metzger, G. (1999) Distinct ethylene- and tissue-specific regulation of $\beta$-1,3-glucanases and chitinases during pea seed germination. Planta 209, 195-201.

Petruzzelli, L., Coraggio, I. and Leubner-Metzger, G. (2000) Ethylene promotes ethylene biosynthesis during pea seed germination by positive feedback regulation of 1aminocyclopropane-1-carboxylic acid oxidase. Planta 211, 144-149.

Petruzzelli, L., Sturaro, M., Mainieri, D. and LeubnerMetzger, G. (2003) Calcium requirement for ethylenedependent responses involving 1-aminocyclopropane-1-carboxylic acid oxidase in radicle tissues of germinated pea seeds. Plant Cell and Environment (in press).

Pflieger, S., Palloix, A., Caranta, C., Blattes, A. and Lefebvre, V. (2001) Defense response genes co-localize with quantitative disease resistance loci in pepper. Theoretical and Applied Genetics 103, 920-929.

Rezzonico, E., Flury, N., Meins, F. and Beffa, R. (1998) Transcriptional down-regulation by abscisic acid of pathogenesis-related $\beta-1,3$-glucanase genes in tobacco cell cultures. Plant Physiology 117, 585-592.

Schmidt-Puchta, W., Kütemeier, G., Günther, I., Haas, B. and Sänger, H.L. (1989) Cloning and sequence analysis of the $18 \mathrm{~S}$ ribosomal RNA gene of tomato and a secondary structure model of the 18S rRNA of angiosperms. Molecular and General Genetics 219, 17-25.

Shinshi, H., Mohnen, D. and Meins, F. (1987) Regulation of a plant pathogenesis-related enzyme inhibition of chitinase and chitinase mRNA accumulation in cultured tobacco tissues by auxin and cytokinin. Proceedings of the National Academy of Sciences, USA 84, 89-93.

Shinshi, H., Wenzler, H., Neuhaus, J.-M., Felix, G., Hofsteenge, J. and Meins, F. (1988) Evidence of N- and C-terminal processing of a plant defense-related enzyme: Primary structure of tobacco prepro- $\beta-1,3-$ glucanase. Proceedings of the National Academy of Sciences, USA 85, 5541-5545.

Simmons, C.R. (1994) The physiology and molecular biology of plant 1,3- $\beta$-D-glucanases and 1,3;1,4- $\beta$-Dglucanases. Critical Reviews in Plant Sciences 13, 325-387.

Sink, K.C. (1984) Petunia. Berlin, Springer-Verlag.

Sperisen, C., Ryals, J. and Meins, F. (1991) Comparison of cloned genes provides evidence for intergenomic exchange of DNA in the evolution of a tobacco glucan endo-1,3- $\beta$-glucosidase gene family. Proceedings of the National Academy of Sciences, USA 88, 1820-1824.

Toorop, P.E., van Aelst, A.C. and Hilhorst, H.W.M. (1998) Endosperm cap weakening and endo- $\beta$-mannanase activity during priming of tomato (Lycopersicon esculentum cv. Moneymaker) seeds are initiated upon crossing a threshold water potential. Seed Science Research 8, 483-491.

Toorop, P.E., van Aelst, A.C. and Hilhorst, H.W.M. (2000) The second step of the biphasic endosperm cap weakening that mediates tomato (Lycopersicon esculentum) seed germination is under control of ABA. Journal of Experimental Botany 51, 1371-1379.

Van Buuren, M., Neuhaus, J.M., Shinshi, H., Ryals, J. and Meins, F. (1992) The structure and regulation of homologous tobacco endochitinase genes of Nicotiana sylvestris and N. tomentosiformis origin. Molecular and General Genetics 232, 460-469.

Van de Rhee, M.D., Lemmers, R. and Bol, J.F. (1993) Analysis of regulatory elements involved in stressinduced and organ-specific expression of tobacco acidic and basic $\beta$-1,3-glucanase genes. Plant Molecular Biology 21, 451-461.

Van Kan, J.A.L., Joosten, M.H.A.J., Wagemakers, C.A.M., van den Berg-Velthuis, G.C.M. and de Wit, P.J.G.M. (1992) Differential accumulation of mRNAs encoding extracellular and intracellular PR proteins in tomato induced by virulent and avirulent races of Cladosporium fulvum. Plant Molecular Biology 20, 513-527.

Vögeli-Lange, R., Fründt, C., Hart, C.M., Nagy, F. and Meins, F. (1994) Developmental, hormonal, and pathogenesis-related regulation of the tobacco class I $\beta$ 1,3-glucanase B promoter. Plant Molecular Biology 25, 299-311.

Watkins, J.T. and Cantliffe, D.J. (1983) Mechanical resistance of the seed coat and endosperm during germination of Capsicum annuum at low temperature. Plant Physiology 72, 146-150. 
Watkins, J.T., Cantliffe, D.J., Huber, D.J. and Nell, T.A. (1985) Gibberellic acid stimulated degradation of endosperm in pepper. Journal of the American Society for Horticultural Science 110, 61-65.

Wu, C.-T. and Bradford, K.J. (2002) Class I chitinase is expressed specifically in the micropylar region of gib-1 tomato seeds in response to wounding or methyl jasmonate. Abstract of the Seventh International Workshop on Seeds, Salamanca, Spain.
Wu, C.-T., Leubner-Metzger, G., Meins, F. and Bradford, K.J. (2000) Class I $\beta$-1,3-glucanase and chitinase are expressed in the micropylar endosperm of tomato seeds prior to radicle emergence. Plant Physiology 126, 1299-1313.

Received 10 July 2002

accepted after revision 8 January 2003

(C) CAB International 2003 